\title{
NITROGÊNIO, CARBONO E COMPACTAÇÃO DO SOLO COMO FATORES LIMITANTES DO PROCESSO DE RECUPERAÇÃO DE MATAS CILIARES ${ }^{(1)}$
}

\author{
Rafael Leandro de Figueiredo Vasconcellos ${ }^{(2)}$, Daniel Bini ${ }^{(3)}$, Alessandra Monteiro de \\ Paula $^{(4)}$, Joice Bonfim Andrade ${ }^{(3)} \&$ Elke Jurandy Bran Nogueira Cardoso(5)
}

\section{RESUMO}

\begin{abstract}
A recuperação de áreas de floresta, principalmente de matas ciliares, tornouse fator-chave para a adequação ambiental da agricultura, com o propósito de proteger os recursos hídricos e a biota. Entretanto, o cultivo agrícola tradicional, além de ter alterado a ciclagem de nutrientes com a perda de matéria orgânica, biomassa e atividade microbiana, causou também a compactação do solo, o que influencia a posterior implantação de reflorestamentos. $O$ objetivo deste trabalho foi identificar quais atributos do solo (físicos, químicos e microbiológicos) mais influenciam o teor de $\mathrm{C}, \mathrm{N}, \mathrm{P}$ e umidade da serapilheira em áreas de mata ciliar com diferentes idades de recuperação ( 20,10 e cinco anos), em comparação com uma área nativa (NT). A partir da ANOVA e dos testes de médias (Duncan) e correlação (Pearson), foram verificados quais atributos acompanham o tempo de recuperação e qual a relação entre eles. A análise multivariada de partição da inércia a partir da análise de redundância (pRDA) foi feita a fim de identificar quais atributos do solo foram mais importantes para discriminar entre as áreas, com base nos teores de $\mathrm{C}, \mathrm{N}, \mathbf{P}$ e umidade da serapilheira encontrados nessas áreas. Maior relação $\mathrm{C} / \mathrm{N}$ da serapilheira foi encontrada nas áreas de $20(26,8)$ e de cinco $(29,9)$ anos. Entre os atributos microbiológicos avaliados, observou-se que a respiração basal do solo $\left(\mathrm{C}-\mathrm{CO}_{2}\right)$, o carbono da biomassa microbiana (CBM) e a atividade das enzimas desidrogenase e urease foram diretamente proporcionais ao aumento da idade das áreas. $\mathrm{O}$ C e $\mathrm{N}$ totais do solo, o $\mathrm{N}-\mathrm{NO}_{3}$, o nitrogênio da biomassa microbiana (NBM), a atividade das enzimas desidrogenase e urease, bem como a macroporosidade correlacionaram-se positivamente e a microporosidade, negativamente, com o $\mathrm{C}$ e $\mathrm{N}$ da serapilheira. A partir da pRDA, o NBM e o carbono
\end{abstract}

\footnotetext{
(1) Recebido para publicação em 21 de novembro de 2012 e aprovado em 25 de junho de 2013.

${ }^{(2)}$ Doutor em Solos e Nutrição de Plantas, Departamento de Ciência do Solo - DCS, Escola Superior de Agricultura "Luiz de Queiroz" - ESALQ/USP. Av. Pádua Dias, 11. CEP 13418-900 Piracicaba (SP), Brasil. E-mail: rlfvasc@usp.br

(3) Doutorandos em Solos e Nutrição de Plantas, DCS/ESALQ/USP. E-mail: dani_bini@yahoo.com.br; joice.agro@yahoo.com.br

(4) Professora Adjunta, Universidade Federal do Paraná, Campus Palotina. Rua Pioneiro, 2153, Jardim Dallas. CEP 85950-000 Palotina (PR), Brasil. E-mail: ampaula21@gmail.com

(5) Professora Titular Aposentada, DCS/ESALQ/USP. E-mail: ejbncard@usp.br
} 
total do solo foram os atributos mais importantes para explicar o teor de $\mathrm{N}$ e $\mathrm{C}$ da serapilheira; a explicação compartilhada foi mais da metade de toda a explicação observada ou 28,2\%. A melhoria das condições físicas do solo e a adição de matéria orgânica que resultam na formação de uma serapilheira mais rica em $\mathbf{N}$ pode ser uma forma de melhorar as condições microbiológicas e químicas do solo e de acelerar o processo de recuperação.

Termos de indexação: atividades da desidrogenase e urease, biomassa microbiana, ciclagem de nutrientes, compactação do solo, recuperação de áreas degradadas.

\title{
SUMMARY: SOIL NITROGEN, CARBON AND COMPACTION AS LIMITING FACTORS FOR THE RECOVERY OF DEGRADED RIPARIAN FORESTS
}

\begin{abstract}
Forest recovery, especially of riparian forests, has become a key factor in the environmental planning of agriculture, to protect water resources and the biota. However, traditional agricultural crops have not only affected nutrient cycling by the loss of organic matter and of microbial biomass and activity, but also increased soil compaction, which can later affect reforestation. The aim of this study was to identify the soil (physical, chemical and microbiological) properties that most influence the litter moisture contents of $C, N$, and $P$ in areas of recovering riparian forests $(20,10$ and 5 years old), in comparison with a native site (NT). The analyses ANOVA, Duncan's test and Pearson's correlation were used to identify the properties influenced by time of recovery and to identify the relationship between them. Multivariate analysis and partition of inertia ( $p R D A)$ were used to identify the most important soil properties to explain variations in litter $C, N, P$, and moisture content. The highest litter $C: N$ ratios (26.8 and 29.9, respectively) were found at the recovery sites after 20 and 5 years. Among the microbiological properties, basal respiration $\left(\mathrm{CO}_{2}-\mathrm{C}\right)$, microbial biomass carbon $(M B C)$ and dehydrogenase and urease activities increased with the age of the recovery sites. Soil total $\mathrm{C}$ and $\mathrm{N}, \mathrm{NO}_{3}-\mathrm{N}$, microbial biomass nitrogen (MBN) and dehydrogenase and urease activities showed a positive correlation with litter $C$ and $N$ content, while microporosity shower a negative correlation. According to the $p R D A$ analysis, NBM and soil $C$ were the most important variables to explain litter $C$ and $N$ content. Besides, these variables together explained more than half of the total variation or $28.2 \%$. The improvement of the soil physical conditions and the addition of organic matter with higher $N$ content could be a possibility of improving the soil microbiological and chemical conditions and accelerate the recovery process.
\end{abstract}

Index terms: dehydrogenase and urease activity, microbial biomass, nutrient cycling, soil compaction, land restoration.

\section{INTRODUÇÃo}

Historicamente, grandes áreas florestais foram substituídas por culturas agrícolas para permitir a produção de alimentos. No entanto, com o melhoramento dessas culturas, em razão do avanço científico e tecnológico, a cada safra tem-se alcançado maiores produtividades em uma mesma área cultivada, reduzindo a pressão da expansão de áreas produtivas sobre áreas florestais nativas (Goldewijk \& Ramankutty, 2007). Nesse sentido, muitas áreas florestais convertidas em áreas agrícolas e pastagens encontram-se hoje em processo de recuperação, demandando uma série de práticas e informações que viabilizem o restabelecimento da comunidade vegetal, associada à manutenção dos processos da microbiota do solo, como a ciclagem de nutrientes.
A floresta atlântica brasileira encontra-se totalmente fragmentada, possuindo mais de $80 \%$ dos fragmentos com menos de 50 ha e com apenas $1 \%$ de floresta intacta (Ribeiro et al., 2009). Dentre os vários ecossistemas impactados pela ação antrópica, destacam-se as matas ciliares, que são fundamentais para proteger os rios do assoreamento e da erosão dos solos, além de funcionar como refúgio para a fauna e como corredores ecológicos, ainda protegendo os animais bentônicos (Bagatini et al., 2012). As matas ciliares são inclusive classificadas como áreas de preservação permanente pelo código florestal (Lei $\mathrm{n}^{\mathrm{o}}$ 12651/12), o que torna a recuperação delas uma obrigatoriedade. Com isso, essas matas, antes utilizadas como pasto e lavoura, necessitam ser recuperadas para que suas funções sejam restabelecidas.

Um planejamento prévio e amplo conhecimento da 
área são fundamentais para o processo de recuperação. Após a escolha e delimitação do local, é importante conhecer o histórico de uso do solo e escolher as espécies nativas a serem plantadas. No desenvolvimento inicial das plantas, o majejo deve visar o controle de pragas como formigas cortadeiras e a melhoria das condições edáficas, como descompactação, aumento do teor de matéria orgânica, regulação do $\mathrm{pH}$, aumento da CTC e do teor de nutrientes limitantes como $\mathrm{P}$ e N .

A conversão de áreas florestais em áreas de produção agrícola altera a dinâmica da ciclagem de nutrientes no sistema solo-planta-atmosfera, refletindo diretamente na diminuição da matéria orgânica do solo (MOS) (Murty et al., 2002). De acordo com esses autores, a conversão de áreas florestais em áreas de cultivo ocasiona perda média de $22 \%$ do carbono armazenado na MOS, com consequências diretas na ciclagem de macronutrientes como o $\mathrm{N}$ e o P. Além disso, a compactação do solo, em razão da redução da porosidade desse, influencia negativamente o processo de recuperação ao impedir o desenvolvimento radicular e estimular a desnitrificação e a redução da aeração e atividade microbiana dele (Silva et al., 2011), interferindo na decomposição da matéria orgânica e ciclagem de nutrientes.

O processo de decomposição é essencial para a manutenção da fertilidade do solo em áreas sob processo de recuperação recente (Prescott, 2005). É na serapilheira que se encontra a etapa crítica da ciclagem de nutrientes em ecossistemas florestais (Prescott, 2005), visto que sua qualidade e diversidade são fundamentais para a manutenção da ciclagem biogeoquímica, em que os microrganismos têm papel fundamental. Atividade enzimática, como a da desidrogenase e a da urease, também está envolvida com a ciclagem de nutrientes, com carbono (C) e $\mathrm{N}$ do solo, sendo sensível ao impacto ambiental (Chodak \& Nikliñska, 2010).

Em florestas tropicais, a qualidade dos compostos de $\mathrm{C}$ é o fator mais determinante da taxa de decomposição, em relação a diferentes razões de $\mathrm{C} / \mathrm{N}$ e N/P da serapilheira (Hättenschwiler \& Jørgensen, 2010), o que indica grande influência dos compostos de $\mathrm{C}$ na capacidade da microbiota em decompor a serapilheira. Outros trabalhos também têm destacado a influência da composição da serapilheira sobre os atributos microbiológicos, como o teor de $\mathrm{C}$ e o de $\mathrm{N}$ microbianos (Ndaw et al., 2009).

Durante o processo de recuperação ambiental, a qualidade da serapilheira dependerá diretamente de um manejo adequado do solo e das espécies vegetais utilizadas no processo de recuperação. Em razão disso, os impactos causados, por exemplo, pela compactação do solo e, ou, perdas de nutrientes, influenciarão na qualidade da serapilheira e retardarão o processo de recuperação.

Objetivou-se com este trabalho avaliar a interação entre alguns atributos microbiológicos, químicos e físicos do solo e os principais nutrientes da serapilheira
$(\mathrm{C}, \mathrm{N}$ e $\mathrm{P})$, para identificar quais atributos influenciam a composição da serapilheira e ainda evidenciar quais nutrientes são mais limitantes no processo de recuperação ambiental.

\section{MATERIAL E MÉTODOS}

\section{Áreas de Estudo}

Uma área nativa de floresta estacional semidecídua (NT) foi comparada com três áreas com diferentes tempos de recuperação, cinco (R05), 10 (R10) e 20 (R20) anos, localizadas no Estado de São Paulo, Brasil (Figura 1) (Quadro 1). O clima local é o Cwa com precipitação pluvial média entre 1.100 e $1.700 \mathrm{~mm}$ anuais, com duas estações bem definidas: inverno seco e verão chuvoso, segundo a classificação de Köppen.

As amostras de solo foram coletadas em janeiro de 2010 , na profundidade de $0-20 \mathrm{~cm}$, e as de serapilheira, em quadrantes de $25 \times 25 \mathrm{~cm}$. Selecionaram-se 15 quadrantes com $10 \times 10 \mathrm{~m}$ dentre os 30 demarcados nas quatro áreas de estudo.

\section{Avaliação dos atributos químicos e físicos do solo e da serapilheira}

A densidade do solo, a macroporosidade, a microporosidade e as frações silte, argila e areia foram analisadas a partir de amostras indeformadas com auxilio de anéis de aço inox na profundidade de $0-5 \mathrm{~cm}$, segundo Embrapa (1997). As amostras foram saturadas em bandejas contendo água até dois terços dos anéis e submetidas a potenciais de pressão de -1 e $-6 \mathrm{kPa}$, em mesa de tensão. A macroporosidade foi determinada pela diferença entre o solo saturado e submetido à pressão de $-6 \mathrm{kPa}$ e a microporosidade, pela tensão em $-6 \mathrm{kPa}$. Após secagem em $105{ }^{\circ} \mathrm{C}$ por $48 \mathrm{~h}$, as amostras foram pesadas e a densidade do solo calculada.

Amostras de solo foram secas em estufa $\left(105^{\circ} \mathrm{C}\right)$, peneiradas $(4 \mathrm{~mm})$ e utilizadas para fazer a análise

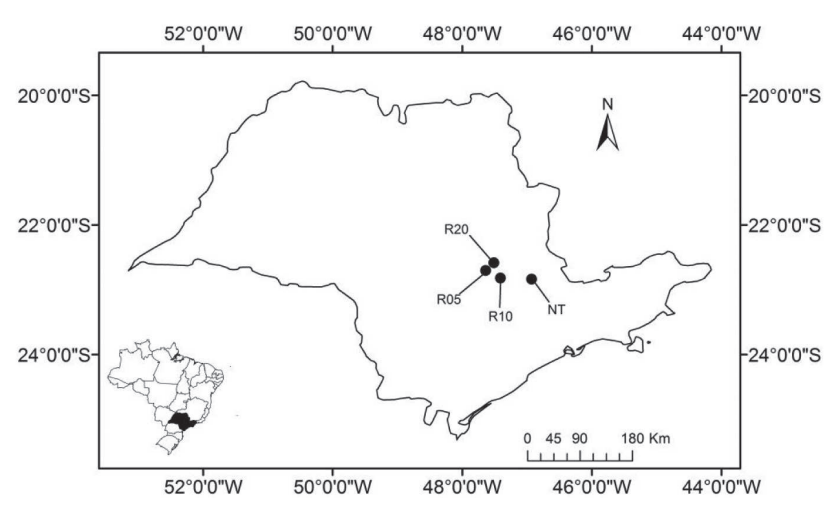

Figura 1. Mapa com a localização das quatro áreas de estudo: mata nativa (NT), e áreas em recuperação a $20(\mathbf{R 2 0}), 10(\mathbf{R 1 0})$ e cinco $(\mathbf{R 0 5})$ anos. 


\section{Quadro 1. Principais características das áreas estudadas}

\begin{tabular}{|c|c|c|c|c|}
\hline Área & NT & $\mathbf{R 2 0}$ & R10 & R05 \\
\hline Localização geográfica & $\begin{array}{l}\text { Ribeirão Cachoeira, SP } \\
22^{\circ} 50^{\prime} 13^{\prime \prime} \mathrm{S} \\
6^{\circ} 55^{\prime} 58^{\prime \prime} \mathrm{W}\end{array}$ & $\begin{array}{l}\text { Iracemápolis, SP } \\
22^{\circ} 35^{\prime} \mathrm{S} \\
47^{\circ} 31^{\prime} \mathrm{W}\end{array}$ & $\begin{array}{l}\text { Santa Bárbara } \\
\text { D’Oeste, SP } \\
22^{\circ} 49^{\prime} 06 \mathrm{~S} \\
47^{\circ} 24^{\prime} 52.89^{\prime \prime} \mathrm{W}\end{array}$ & $\begin{array}{l}\text { Às margens do } \\
\text { rio Piracicaba } \\
22^{\circ} 42^{\prime} 02^{\prime \prime} \mathrm{S} \\
47^{\circ} 38^{\prime} 32^{\prime \prime} \mathrm{W}\end{array}$ \\
\hline Tempo de recuperação & nativa & 20 anos & 10 anos & 5 anos \\
\hline Tamanho da área & 233 ha & 50 ha & 10 ha & $\approx 16 \mathrm{ha}$ \\
\hline Altura média de dossel & $20-30 \mathrm{~m}$ & $\approx 8 \mathrm{~m}$ & $\approx 5-8 \mathrm{~m}$ & $\approx 5 \mathrm{~m}$ \\
\hline $\begin{array}{l}\text { Forma de plantio e } \\
\text { número de espécies }\end{array}$ & $\approx 170$ espécies & $\begin{array}{l}3 \times 3 \text { m; } \\
140 \text { espécies }\end{array}$ & $\begin{array}{l}3 \text { × } 2 \text { m; } 80 \text { espécies; } \\
\text { presença de gramíneas }\end{array}$ & $\begin{array}{l}3 \times 3 \mathrm{~m} \\
\approx 80 \text { espécies; } \\
\text { presença de } \\
\text { gramíneas }\end{array}$ \\
\hline Principais espécies & $\begin{array}{l}11 \text { famílias [Myrtaceae } \\
\text { (14 espécies), Rutaceae } \\
\text { e Fabaceae (13), } \\
\text { Solanaceae (9), } \\
\text { Rubiaceae (8), Moraceae, } \\
\text { Meliaceae and } \\
\text { Euphorbiaceae ( } 7 \text { ), } \\
\text { Lauraceae e } \\
\text { Mimosaceae (6)] } \\
\text { equivalente a } 58 \% \\
\text { das espécies amostradas }\end{array}$ & \multicolumn{3}{|c|}{$\begin{array}{l}\text { (1) } 14 \text { famílias arbóreas [Annonaceae (1 espécie), Apocynaceae (3), } \\
\text { Boraginaceae (1), Caesalpinaceae (2), Caricaceae (1), Fabaceae (7), } \\
\text { Flacourtiaceae (1), Lauraceae (1), Lecythidaceae (1), Malvaceae (1), } \\
\text { Meliaceae (2), Rutaceae (3) Rosaceae (1), e Verbanaceae (1) }\end{array}$} \\
\hline Solo $^{(2)}$ & $\begin{array}{l}\text { Argisolo } \\
\text { Vermelho-Amarelo }\end{array}$ & $\begin{array}{l}\text { Latosolo Vermelho } \\
\text { distroférrico }\end{array}$ & Argisolo Amarelo & $\begin{array}{l}\text { Nitossolo Vermelho } \\
\text { eutroférrico }\end{array}$ \\
\hline
\end{tabular}

(1) Famílias e número de espécies geralmente encontrados nas três áreas em recuperação ( R20 e R10 ou R20 e R05). Espécies comuns às três áreas: Balfourodendron riedelianum (Engl.) Engl., Cariniana estrellensis (Raddi) Kunth., Cariniana legalis, Cedrella fissilis e Centrolobium tomentosum Benth; ${ }^{(2)}$ Embrapa (2006). Fonte: Extraído de Rodrigues et al. (1987), Santos \& Kinoshita (2003), Amazonas et al. (2011) e Bertacchi (2012).

química do solo, seguindo os métodos de Raij et al. (2001) e sendo avaliados: $\mathrm{pH}$ do solo em $\mathrm{KCl}$ e em $\mathrm{H}_{2} \mathrm{O}$, $\mathrm{P}$ disponível (resina), $\mathrm{K}^{+}$(Mehlich-1), $\mathrm{Al}^{3+}(\mathrm{KCl})$, $\mathrm{H}+\mathrm{Al}$ (SMP), $\mathrm{Ca}^{2+}$ (resina), $\mathrm{Mg}^{2+}$ (resina), $\mathrm{SB}$ (soma de bases) e CTC (capacidade de troca de cátions método indireto) (Quadro 2).

Os carbono $(\mathrm{C})$ e nitrogênio $(\mathrm{N})$ totais do solo e os da serapilheira foram avaliados pelo método de combustão total, utilizando-se o analisador elementar LECO-CN 2000. Para essa análise, o solo e a serapilheira foram secos a $45^{\circ} \mathrm{C}$ por $48 \mathrm{~h}$ e moídos. Avaliaram-se os teores de $\mathrm{N}-\mathrm{NH}_{4}$ e N-NO $\mathrm{N}_{3}$ do solo por destilação, utilizando o solo úmido (Keeney \& Nelson, 1982); e o teor de P da serapilheira, segundo Murphy \& Riley (1962). A umidade da serapilheira foi avaliada pela diferença entre a amostra in natura e a seca a $45^{\circ} \mathrm{C}$, por $48 \mathrm{~h}$.

\section{Avaliação dos atributos microbiológicos do solo}

Para a análise microbiológica, as amostras de solo foram armazenadas em câmara fria em sacos plásticos e analisadas no máximo uma semana após a coleta, sendo essas mantidas em temperatura ambiente por até $12 \mathrm{~h}$ antes dos ensaios. Para determinar o carbono da biomassa microbiana (CBM) e o nitrogênio da biomassa microbiana (NBM), utilizouse o método de fumigação-extração (Vance et al., 1987). O NBM foi quantificado pelo método da ninhidrina (Joergensen \& Brookes, 1990). Para os cálculos, foram utilizados os coeficientes de conversão de $\mathrm{kc}=0,4$ para CBM e kn = 0,54 para NBM (Kaschuk et al., 2010).

$\mathrm{A}$ atividade microbiana foi determinada pela respiração basal $\left(\mathrm{C}_{-} \mathrm{CO}_{2}\right)$ em amostras de $50 \mathrm{~g}$ de solo, incubadas por 20 dias a $28{ }^{\circ} \mathrm{C}$. O CO 2 liberado foi quantificado por titulação, segundo Alef (1995). As enzimas analisadas foram a desidrogenase (Casida et al., 1964) e urease (EC 3.5.1.5.) (Tabatabai \& Bremner, 1969).

\section{Análise Estatística}

$\mathrm{O}$ teor de $\mathrm{N}-\mathrm{NO}_{3}, \mathrm{~N}-\mathrm{NH}_{4}, \mathrm{C}$ total e $\mathrm{N}$ total do solo e da serapilheira e o $\mathrm{P}$ da serapilheira, além do CBM, $\mathrm{NBM}, \mathrm{C}-\mathrm{CO}_{2}$, atividade da urease e da desidrogenase, foram submetidos à análise de variância (ANOVA) e 
Quadro 2. Atributos físicos e químicos dos solos da floresta nativa (NT) e das áreas em recuperação. Valores médios (n= 3 para silte, argila e areia e $n=15$ para as demais) e desvio-padrão são apresentados

\begin{tabular}{|c|c|c|c|c|}
\hline Variável & NT & 20 anos & 10 anos & 5 anos \\
\hline Densidade do solo $\left(\mathrm{g} \mathrm{cm}^{-3}\right)^{(1)}$ & $1,33 \pm 0,15 \mathrm{~b}$ & $1,37 \pm 0,09 \mathrm{~b}$ & $1,57 \pm 0,10 \mathrm{a}$ & $1,58 \pm 0,07 \mathrm{a}$ \\
\hline Macroporosidade $\left(\mathrm{m}^{3} \mathrm{~m}^{-3}\right)^{(1)}$ & $0,21 \pm 0,06 \mathrm{a}$ & $0,1 \pm 0,04 \mathrm{~b}$ & $0,09 \pm 0,04 \mathrm{~b}$ & $0,05 \pm 0,02 \mathrm{c}$ \\
\hline Microporosidade $\left(\mathrm{m}^{3} \mathrm{~m}^{-3}\right)^{(1)}$ & $0,27 \pm 0,07 \mathrm{c}$ & $0,41 \pm 0,03 \mathrm{a}$ & $0,32 \pm 0,02 \mathrm{~b}$ & $0,41 \pm 0,02$ \\
\hline Silte $\left(\mathrm{g} \mathrm{kg}^{-1}\right)$ & $137 \pm 33,5$ & $71 \pm 28,6$ & $54 \pm 29,5$ & $135 \pm 21,08$ \\
\hline Argila $\left(\mathrm{g} \mathrm{kg}^{-1}\right)$ & $251 \pm 0,01$ & $584 \pm 38,2$ & $301 \pm 50$ & $534 \pm 28,87$ \\
\hline Areia total $\left(\mathrm{g} \mathrm{kg}^{-1}\right)$ & $612 \pm 33,5$ & $345 \pm 62,45$ & $646 \pm 62,7$ & $331 \pm 43,7$ \\
\hline $\mathrm{pH}\left(\mathrm{H}_{2} 0\right)(1: 1)$ & $5,16 \pm 0,57$ & $5,01 \pm 0,49$ & $5,64 \pm 0,24$ & $5,26 \pm 0,24$ \\
\hline $\mathrm{pH}(\mathrm{KCl})\left(0,01 \mathrm{~mol} \mathrm{~L}^{-1}\right)$ & $4,46 \pm 0,69$ & $4,25 \pm 0,22$ & $4,71 \pm 0,29$ & $4,41 \pm 0,28$ \\
\hline $\mathrm{H}+\mathrm{Al}\left(\mathrm{mmol}_{\mathrm{c}} \mathrm{dm}^{-3}\right)$ & $53,87 \pm 20,26$ & $33,7 \pm 3,74$ & $80,2 \pm 25,45$ & $61,07 \pm 10$ \\
\hline $\mathrm{Al}^{3+}\left(\mathrm{mmol}_{\mathrm{c}} \mathrm{dm}^{-3}\right)$ & $5,16 \pm 2,22$ & $2,25 \pm 0,83$ & $4,5 \pm 3,28$ & $1,85 \pm 0,3$ \\
\hline $\mathrm{CTC}\left(\mathrm{mmol}_{\mathrm{c}} \mathrm{dm}^{-3}\right)$ & $218,37 \pm 37,8$ & $100,47 \pm 11,4$ & $305,8 \pm 41,9$ & $154,8 \pm 20,2$ \\
\hline $\mathrm{K}^{+}\left(\mathrm{mmol}_{\mathrm{c}} \mathrm{dm}^{-3}\right)$ & $117,1 \pm 33,87$ & $40,13 \pm 12,91$ & $195,4 \pm 39,16$ & $43,5 \pm 16,94$ \\
\hline $\mathrm{Ca}^{2+}\left(\mathrm{mmol}_{\mathrm{c}} \mathrm{dm}^{-3}\right)$ & $36,53 \pm 24,68$ & $17,87 \pm 4,72$ & $22,7 \pm 15,43$ & $39,7 \pm 12,95$ \\
\hline $\mathrm{Mg}^{2+}\left(\mathrm{mmol}_{\mathrm{c}} \mathrm{dm}^{-3}\right)$ & $10,87 \pm 3,87$ & $8,8 \pm 2,78$ & $7,53 \pm 4,76$ & $10,53 \pm 3,0$ \\
\hline $\mathrm{SB}\left(\mathrm{mmol}_{\mathrm{c}} \mathrm{dm}^{-3}\right)$ & $164,5 \pm 52,55$ & $66,8 \pm 10,97$ & $225,6 \pm 49,38$ & $93,73 \pm 22,2$ \\
\hline $\mathrm{P}$ disponível $\left(\mathrm{mg} \mathrm{dm}{ }^{-3}\right)$ & $13,14 \pm 3,73$ & $4,53 \pm 1,2$ & $22,87 \pm 10,0$ & $16,27 \pm 8,12$ \\
\hline
\end{tabular}

(1) Valores seguidos pela mesma letra não diferem entre si pelo teste de Duncan $(p \leq 0,05)$; CTC: capacidade de troca de cátions, SB: saturação por base e P: fósforo disponível.

comparados pelo teste de Duncan $(\mathrm{p} \leq 0,05)$ e pela correlação de Pearson $(p<0,05)$, utilizando-se o aplicativo SAS 9.2 (SAS, 1999).

Para identificar quais grupos de variáveis ambientais poderiam explicar os dados de $\mathrm{C}, \mathrm{N}$ e $\mathrm{P}$ da serapilheira, utilizou-se a partição da variância a partir da análise de Redundância (pRDA). A decomposição da variância foi feita por utilização de variáveis separadas entre variáveis ambientais com ou sem covariáveis (Borcard et al., 1992). As variáveis ambientais foram separadas em três grupos: I - físicas (densidade do solo, macro e microporosidade), II químicas (carbono e nitrogênio do solo, $\mathrm{N}_{-} \mathrm{NH}_{4}, \mathrm{~N}-$ $\mathrm{NO}_{3}$, fósforo disponível do solo e $\mathrm{SB}$ ) e III microbiológicas (CBM, NBM, C- $\mathrm{CO}_{2}$, atividades da desidrogenase e da urease). A significância estatística da pRDA foi avaliada pelo teste de Permutação de Monte Carlo $(p<0,05)$. A partir do método de "forward selection", as variáveis que foram significativas $(\mathrm{p}<0,05)$ foram utilizadas para fazer a análise de Redundância (RDA) final. A atividade da desidrogenase foi retirada da análise por causa do efeito de multicolinearidade. As análises multivariadas foram realizadas com auxílio do programa Canoco 4.5 (Ter Braak \& Smilauer, 1998).

\section{RESULTADOS}

Em relação às características do solo, observaramse diferenças no tipo de solo, na densidade do solo e na macroporosidade. Latossolos são caracterizados por apresentar teor de argila relativamente uniforme ao longo do perfil e, consequentemente, macro e microporosidade também proporcionais ao longo do perfil, enquanto Argissolos tendem a apresentar macroporosidade maior nas camadas superficiais, como consequência da migração da argila para 0 horizonte subsuperficial diagnóstico. Já os Nitossolos são distinguidos por teores de argila acima de $60 \%$, com estrutura em blocos ou prismática bem desenvolvida, com predomínio de microporosidade e podendo apresentar discreto aumento no teor de argila em profundidade (Oliveira, 1999). A microporosidade do solo evidenciou-se semelhante entre as áreas NT e R10 (textura média) e entre R20 e R05 (argiloso). Contudo, a macroporosidade foi maior na área NT e semelhante entre as áreas mais antigas em recuperação (R20 e R10) (Quadro 2).

Os atributos que acompanharam o tempo de recuperação ou foram maiores nas áreas mais antigas são $\mathrm{C}$ total do solo, $\mathrm{N}_{-} \mathrm{NO}_{3}, \mathrm{CBM}, \mathrm{C}-\mathrm{CO}_{2}$ e atividades da urease e desidrogenase $(p \leq 0,05)$ (Quadro 3). Entretanto, o NBM não diferiu entre as áreas em recuperação e o teor de $\mathrm{N}-\mathrm{NH}_{4}$ divergiu apenas entre NT e R10, em relação à área R05.

$\mathrm{O}$ teor de $\mathrm{C}$ e o de $\mathrm{N}$ da serapilheira foram maiores na área NT e seguiu da área em recuperação mais nova (R05) para a mais antiga (R20) (Quadro 3). O teor de $\mathrm{P}$ na serapilheira foi maior nas áreas R05 e R20 (Quadro 3). A relação $\mathrm{C} / \mathrm{N}$ da serapilheira encontrada nas áreas foi: $\mathrm{NT}=18,52 ; \mathrm{R} 20=26,8$; $\mathrm{R} 10=23,27 ;$ e $\mathrm{R} 05=29,9$ e a relação $\mathrm{C}: \mathrm{P}$ da serapilheira, $\mathrm{NT}=585 ; \mathrm{R} 20=211 ; \mathrm{R} 10=441 ; \mathrm{e}$ R05 $=275$. 
Quadro 3. Atributos químicos do solo (carbono total, nitrogênio total, $\mathrm{N}-\mathrm{NO}_{3}$ e $\mathrm{N}-\mathrm{NH}_{4}$ ), da serapilheira (carbono total, nitrogênio total e fósforo) e microbiológicos do solo (CBM, NBM, atividades da urease e da desidrogenase e respiração basal do solo), da floresta nativa (NT) e das áreas em recuperação

\begin{tabular}{|c|c|c|c|c|}
\hline Atributo & NT & 20 anos & 10 anos & 5 anos \\
\hline & \multicolumn{4}{|c|}{ Solo } \\
\hline Carbono total $(\%)$ & $3,9 \pm 0,26 \mathrm{a}$ & $2,4 \pm 0,13 \mathrm{~b}$ & $2,3 \pm 0,12 \mathrm{bc}$ & $1,9 \pm 0,04 \mathrm{c}$ \\
\hline Nitrogênio total (\%) & $0,34 \pm 0,03 \mathrm{a}$ & $0,16 \pm 0,007 \mathrm{~b}$ & $0,11 \pm 0,01 \mathrm{c}$ & $0,15 \pm 0,05 \mathrm{~b}$ \\
\hline $\mathrm{N}-\mathrm{NO}_{3}\left(\mu \mathrm{g} \mathrm{g}^{-1}\right)$ & $18,39 \pm 1,75 \mathrm{a}$ & $9,67 \pm 0,93 \mathrm{~b}$ & $5,91 \pm 0,7 \mathrm{c}$ & $2,68 \pm 0,5 \mathrm{~d}$ \\
\hline $\mathrm{N}-\mathrm{NH}_{4}\left(\mu \mathrm{g} \mathrm{g}^{-1}\right)$ & $8,05 \pm 1,8 \mathrm{a}$ & $5,62 \pm 1,08 \mathrm{ab}$ & $7,62 \pm 1,3 \mathrm{a}$ & $3,27 \pm 0,65 b$ \\
\hline CBM ( $\mu g^{-1}$ de C no solo) & $209,94 \pm 16,8 \mathrm{a}$ & $172,43 \pm 18,5 \mathrm{a}$ & $109,35 \pm 11,6 \mathrm{~b}$ & $104,18 \pm 10,8 \mathrm{~b}$ \\
\hline NBM ( $\mu g^{-1}$ de $N$ no solo) & $92,41 \pm 6,2 \mathrm{a}$ & $40,24 \pm 2,9 \mathrm{~b}$ & $35,78 \pm 6,4 \mathrm{~b}$ & $35,78 \pm 6,4 \mathrm{~b}$ \\
\hline C- $\mathrm{CO}_{2}\left(\mu \mathrm{g} \mathrm{g}^{-1}\right.$ de $\mathrm{CO}_{2}$ no solo) & $101,2 \pm 6,5 \mathrm{a}$ & $72,0 \pm 7,4 \mathrm{~b}$ & $58,9 \pm 4,4 \mathrm{bc}$ & $47,2 \pm 3,5 \mathrm{c}$ \\
\hline Atividade da desidrogenase ( $\mu \mathrm{g} \mathrm{g}^{-1}$ TTF no solo) & $25,75 \pm 3,0 \mathrm{a}$ & $10,4 \pm 1,0 \mathrm{~b}$ & $9,47 \pm 0,4 \mathrm{~b}$ & $6,0 \pm 0,3 \mathrm{c}$ \\
\hline \multirow[t]{2}{*}{ Atividade da urease ( $\mu \mathrm{g} \mathrm{g}^{-1}$ de $\mathrm{N}$ no solo) } & $185,4 \pm 19,2 \mathrm{a}$ & $134,1 \pm 8,2 \mathrm{a}$ & $83,2 \pm 23,5 \mathrm{~b}$ & $90,6 \pm 8,8 b$ \\
\hline & \multicolumn{4}{|c|}{ Serapilheira } \\
\hline Carbono total $(\%)$ & $40,94 \pm 1,7 \mathrm{a}$ & $27,1 \pm 1,82 \mathrm{c}$ & $29,56 \pm 1,65 \mathrm{bc}$ & $33,04 \pm 1,32 \mathrm{~b}$ \\
\hline Nitrogênio total $(\%)$ & $2,21 \pm 0,12 \mathrm{a}$ & $1,01 \pm 0,06 \mathrm{~d}$ & $1,27 \pm 0,08 \mathrm{c}$ & $1,58 \pm 0,1 b$ \\
\hline$P\left(\mu g^{-1}\right)$ & $0,07 \pm 0,005 b$ & $0,1 \pm 0,008 \mathrm{a}$ & $0,07 \pm 0,005 \mathrm{~b}$ & $0,12 \pm 0,008 \mathrm{a}$ \\
\hline
\end{tabular}

Letras iguais, na mesma linha, não diferem entre si pelo teste de Duncan $(\leq 0,05)$.

O NBM, a atividade da desidrogenase, o $\mathrm{C}$ e o $\mathrm{N}$ totais do solo tiveram correlação com o $\mathrm{C}$ e o $\mathrm{N}$ da serapilheira (Quadro 4). Observou-se também relação negativa da microporosidade e positiva da macroporosidade com o $\mathrm{C}$ e o $\mathrm{N}$ da serapilheira (Quadro 4).

\section{Análise Multivariada}

Dos $28,1 \%$ da variância total explicada por todas as variáveis ambientais, $10,4 \%$ foram explicadas pela intersecção entre os três grupos de variáveis selecionadas (Figura 1a). Os principais grupos que mais explicaram a variância foram as variáveis químicas (SB e C do solo) com $5 \%$ e a variável microbiológica (NBM) com 6,3\%. A macroporosidade sozinha explicou apenas $1,5 \%$ da variância.

A RDA feita com todas as variáveis ambientais selecionadas (figura 1b) indicou o efeito do NBM e da macroporosidade sobre o $\mathrm{C}$ e o $\mathrm{N}$ da serapilheira. Com a RDA, explicaram-se, pelo eixo 1 , os $81,7 \%$ da separação da área nativa daquelas em recuperação (R20, R10 e R05). Foi também importante observar o efeito negativo do $\mathrm{P}$ da serapilheira nas variáveis ambientais (Figura 1b).

\section{DISCUSSÃO}

A baixa concentração de $\mathrm{N}$ da serapilheira encontrada nas áreas R20 e R10 representa um fator limitante relacionado à recuperação ambiental. A maior ciclagem bioquímica de $\mathrm{N}$ em ambientes pobres desse nutriente provocou redução da concentração de $\mathrm{N}$ da serapilheira (Gama-Rodrigues \& Barros,
2002), o que tendeu a aumentar a relação $\mathrm{C} / \mathrm{N}$ do material orgânico e influenciar a mineralização pela microbiota. Essa importante relação entre a atividade microbiana e com os nutrientes da serapilheira foi corroborada pela correlação encontrada entre a atividade da enzima desidrogenase e NBM com o $\mathrm{C}$ e o $\mathrm{N}$ da serapilheira (Quadro 4). A correlação negativa observada entre microporosidade e o $\mathrm{C}$ e o $\mathrm{N}$ da serapilheira indicaram um efeito negativo sobre a ciclagem de nutrientes e influência negativa da compactação sobre a microbiota do solo envolvida na decomposição da matéria orgânica. Em solos compactados ou mais argilosos que apresentam valores observados superiores ao intervalo proposto por Reichert et al. (2003), de 1,25 a 1,30 $\mathrm{Mg} \mathrm{m}^{-3}$, estabelecido a partir do indicador de qualidade estrutural do solo IHO para solos argilosos, como foi o caso das áreas R20 e R05, ocorre maior proteção da matéria orgânica, de modo a reduzir a disponibilidade de nutrientes a partir da mineralização (Silva et al., 2011). Além disso, possivelmente, a maior abundância e diversidade vegetal também tenham contribuído para as diferenças na ciclagem de nutrientes, em relação às demais áreas. Maiores teores de $\mathrm{P}$ também foram encontrados nas áreas R20 e R05. Isso pode ter ocorrido em razão da micorrização e maior atividade de fosfatases ou mesmo por estar relacionado ao histórico das áreas. Contudo, novos estudos são necessários para se chegar à conclusão concreta.

A textura e a compactação do solo podem ter sido importantes para as concentrações de $\mathrm{N}_{-} \mathrm{NO}_{3}$ e N-NH encontradas. Áreas desmatadas tendem a ter menor concentração de $\mathrm{C}$ e de $\mathrm{N}$ em razão da perda por decomposição da matéria orgânica estável e por 
Quadro 4. Coeficiente de correlação entre os atributos microbiológicos (NBM, atividade da desidrogenase), químicos (carbono total e nitrogênio total do solo) e físicos (micro e macroporosidade) do solo, em relação aos valores de carbono total e nitrogênio total da serapilheira

\begin{tabular}{lcc}
\hline \multirow{2}{*}{ Solo } & \multicolumn{2}{c}{ Serapilheira } \\
\cline { 2 - 3 } & C total & N total \\
\hline NBM & $0,63^{* *}$ & $0,65^{* *}$ \\
Atividade da desidrogenase & $0,51^{* *}$ & $0,53^{* *}$ \\
Carbono total & $0,48^{* *}$ & $0,48^{* *}$ \\
Nitrogênio total & $0,46^{*}$ & $0,50^{* *}$ \\
Microporosidade & $-0,44^{*}$ & $-0,49^{* *}$ \\
Macroporosidade & $0,44^{*}$ & $0,54^{* *}$ \\
\hline
\end{tabular}

** e *: diferença significativa a $\leq 0,0001$ e $\leq 0,001$, respectivamente.

lixiviação dos nutrientes, como $\mathrm{N}-\mathrm{NO}_{3}$ (Murty et al., 2002), o que pode explicar a redução gradativa do N$\mathrm{NO}_{3}$ em relação a idade das áreas em recuperação. A compactação do solo (aumento da densidade do solo e da microporosidade), além de interferir negativamente na atividade microbiana, em conjunto com solos com textura mais argilosa, pode reduzir a aeração e estimular os microrganismos desnitrificantes (Jackson et al., 2008; Silva et al., 2011). A transformação do $\mathrm{N}-\mathrm{NH}_{4} \mathrm{em} \mathrm{N}-\mathrm{NO}_{3}$ pelo processo de nitrificação é estimulada pela matéria orgânica e pela maior mineralização (Siqueira Neto et al., 2010). Contudo, a maior relação C: $\mathrm{N}$ da serapilheira na área R20 pode estar influenciando a mineralização de $\mathrm{Ne}$, consequentemente, a concentração final de $\mathrm{N}$ amoniacal.

A respiração basal e o CBM do solo aumentaram concatenados com a idade das áreas e ocorreu uma relação direta com o aumento do $\mathrm{C}$ total do solo. Isso pode ser explicado pelo maior tempo de acúmulo de matéria orgânica estável e também pela maior estabilidade na atividade microbiana. Nesse sentido, o manejo adotado para a recuperação das áreas, com redução da perda de $\mathrm{C}$ e a da compactação do solo, e também buscando maior quantidade e diversidade vegetal e de serapilheira depositada sobre o solo, auxiliou na maior estabilidade da microbiota (Dinesh et al., 2003; Allison \& Jastrow, 2006).

Nas áreas R20, R10 e R05 não houve diferenças em relação à NBM, sendo menores que o valor encontrado em NT. Esse fato pode ser decorrente da necessidade de $\mathrm{N}$ e de condições menos favoráveis ao estabelecimento mais prolongado da biomassa microbiana. Monteiro \& Gama-Rodrigues (2004), estudando a influência nutricional da serapilheira sobre a biomassa microbiana em mata atlântica montana, observaram a importância da qualidade da serapilheira e principalmente do $\mathrm{N}$, para a biomassa microbiana. Além disso, a biomassa microbiana
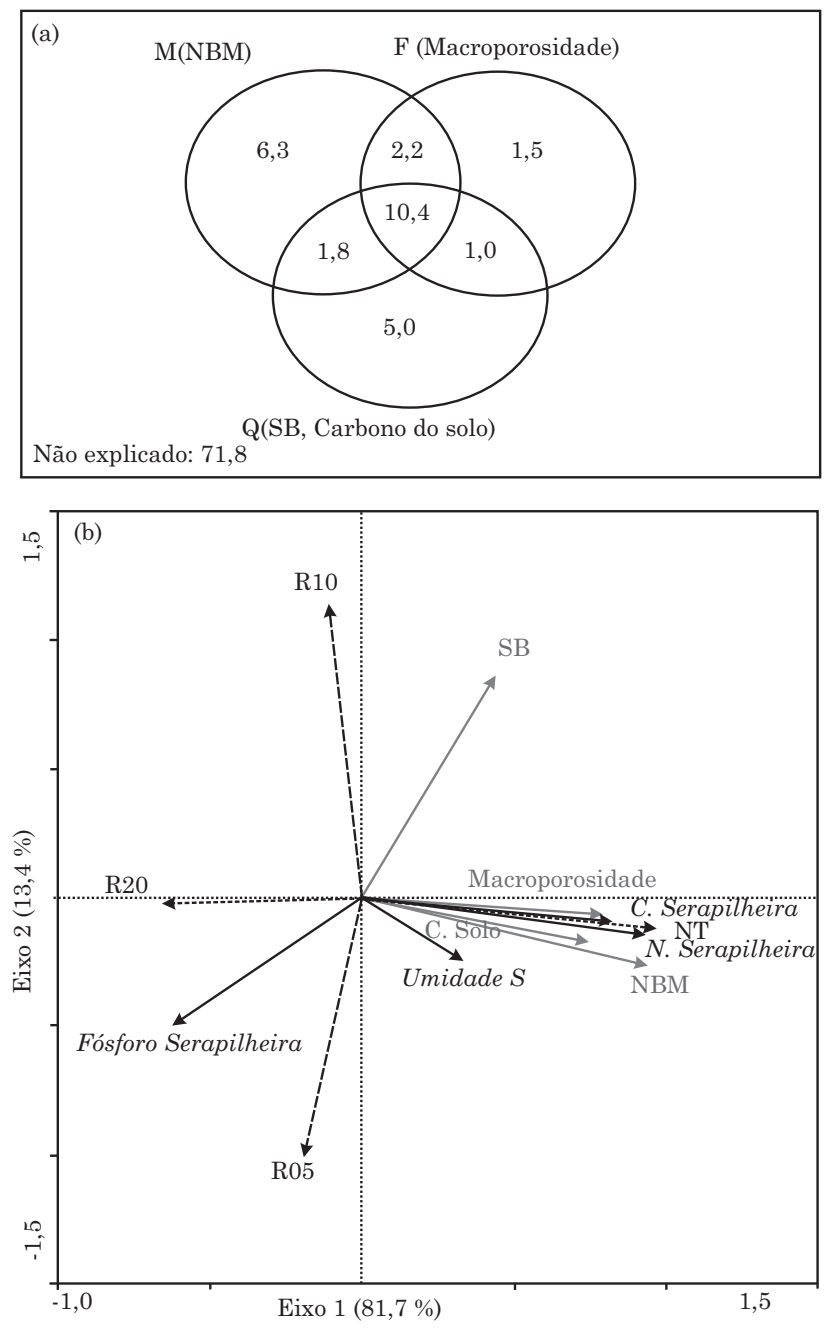

Figura 1. Influência dos atributos físicos, químicos e microbiológicos sobre o carbono (C, Serapilheira), nitrogênio (N, Serapilheira), fósforo da serapilheira e umidade (Umidade $\mathbf{S}$ ) da serapilheira. (a) Decomposição da variância por meio da análise da pRDA das variáveis microbiológica (NBM), física (macroporosidade) e químicas (SB e carbono do solo), (b) RDA das variáveis selecionadas pela pRDA $(p<0,05$, teste de Monte Carlo). As setas de pontos referentes às áreas representam o centroide; as negras, as variáveis da serapilheira; e as cinzas, as variáveis ambientais.

geralmente apresenta maiores valores em ambientes mais estáveis e com maior quantidade de nichos e fontes de matéria orgânica com melhor qualidade (Kaschuk et al., 2010).

A sensibilidade da biomassa microbiana ao tempo de recuperação foi tão evidente quanto aquela observada para a atividade das enzimas desidrogenase e urease. A relação entre atividade da desidrogenase e a da urease com o $\mathrm{C}$ e o $\mathrm{N}$ do solo é amplamente conhecida (Badiane et al., 2001; Nogueira et al., 2006; 
Nayak et al., 2007). Essas enzimas são sensivelmente modificadas por alterações desses atributos do solo e isso pode ser reflexo do tipo de manejo, da qualidade e da quantidade do $\mathrm{C}$ disponível (Chodak \& Nikliñska 2010). No entanto, as relações entre a atividade microbiana do solo e a dos atributos químicos, como $\mathrm{C}$ e $\mathrm{N}$ do solo, com a serapilheira foi influenciada pela diversidade vegetal (Souza et al., 2012). Nesse caso, a utilização de espécies que proporcionem menor relação $\mathrm{C} / \mathrm{N}$ pode auxiliar na maior atividade microbiana do solo e maximizar a ciclagem de nutrientes.

A análise univariada evidenciou que $\mathrm{o} \mathrm{C}$ do solo $\mathrm{e}$ o teor de $\mathrm{N}$ foram importantes para as diferenças encontradas entre as áreas estudadas. A análise de pRDA também mostrou a importância do manejo e da qualidade do material orgânico do solo e da umidade sobre a microbiota e sua interação com os atributos químicos e físicos (Figura 1). Pela pRDA, observou-se que o NBM e os atributos químicos do solo (SB e C orgânico) foram os principais fatores para a discriminação das áreas (Figura 1a). Contudo, a interação desses atributos com a macroporosidade representou mais da metade da explicação da variância. Isso indicou a importância de um manejo adequado, como a descompactação e a melhoria da qualidade do material orgânico e nutricional do solo para uma adequada recuperação ambiental. A NBM, reconhecido indicador de qualidade e manejo do solo (Kaschuk et al., 2010) indicou a necessidade da melhoria das condições físicas e químicas e ainda evidenciou a importância do aporte de $\mathrm{N}$ para a qualidade da serapilheira. De acordo com Pengthamkeerati et al. (2011), a partir do estudo do efeito da compactação do solo, da adição de material orgânico e do manejo da biomassa e atividade microbiana, sugeriu-se que a matéria orgânica pode reduzir os efeitos da compactação sobre a microbiota do solo. O P da serapilheira não foi fator fundamental para explicar a separação das áreas pela idade de recuperação no atual estudo; contudo, é um nutriente limitante para a recuperação de áreas degradadas. A utilização de compostos orgânicos e plantio com mudas micorrizadas são formas importantes para reduzir o efeito da limitação de $\mathrm{P}$ para o desenvolvimento das plantas (Mendes-Filho et al., 2010.).

\section{CONCLUSÕES}

1. A quantidade e a qualidade do nitrogênio da serapilheira refletiram diretamente no aporte de nitrogênio microbiano. Contudo, a atividade microbiana representada pela atividade enzimática, respiração basal e carbono microbiano foi importante para discriminar as áreas quanto à idade de recuperação, mesmo com limitação de $\mathrm{N}$, principalmente em razão do carbono do solo.
2. O nitrogênio da serapilheira foi o principal nutriente limitante para a recuperação das áreas, principalmente devido a influência da compactação.

\section{AGRADECIMENTOS}

À FAPESP, pelo auxilio financeiro para o desenvolvimento desse projeto, e ao $\mathrm{CNPq}$, pela bolsa de produtividade científica concedida à Dra. Elke Jurandy Bran Nogueira Cardoso.

\section{LITERATURA CITADA}

ALEF K. Soil Respiration. In: ALEF, K. \& NANNPIERI, P., eds. Methods in applied soil microbiology and biochemistry. Academic Press: Amsterdam, 1995. p.234-245.

ALLISON, S.D. \& JASTROW, J.D. Activities of extracellular enzymes in physically isolated fractions of restored grassland soils. Soil Biol. Biochem., 38:3245-3256, 2006.

AMAZONAS, N.T.; MARTINELLI, L.A.; PICCOLO, M.C. \& RODRIGUES, R.R. Nitrogen dynamics during ecosystem development in tropical forest restoration. For. Ecol. Manage., 262:1551-1557, 2011.

BADIANE, N.N.Y.; CHOTTE, J.L.; PATE, E.; MASSE, D. \& ROULAND, C. Use of soil enzyme activities to monitor soil quality in natural and improved fallows in semi-arid tropical regions. Appl. Soil Ecol., 18:229-238, 2001.

BAGATINI, Y. M.; DELARIVA, R. L. \& HIGUTI, J. Benthic macroinvertebrate community structure in a stream of the north-west region of Paraná State, Brazil. Biota Neotrop., 12:307-317, 2012.

BERTACCHI, M.I.F. Micro-sítio como filtro para o estabelecimento de regenerantes arbóreos em áreas restauradas. Piracicaba, Escola Superior de Agricultura Luiz de Queiroz, Universidade de São Paulo, 2012. 123p. (Dissertação de Mestrado) Disponível em: <http:// www.teses.usp.br/teses/disponiveis/11/11150/tde14022012-093157/>. Acesso em: 11 set. 2012.

BORCARD, D.; LEGENDRE, P. \& DRAPEAU, P. Partialling out the spatial component of ecological variation. Ecology, 73:1045-1055, 1992.

CASIDA, L.E.; KLEIN, D.A. \& SANTORO, T. Soil dehydrogenase activity. Soil Sci., 98:371-376, 1964.

CHODAK, M. \& NIKLIÑSKA, M. Effect of texture and tree species on microbial properties of mine soils. Appl. Soil Ecol., 46:268-275, 2010.

DINESH, R.; CHAUDHURI, S.G.; GANESHAMURTHY, A.N. \& DEY, C. Changes in soil microbial indices and their relationships following deforestation and cultivation in wet tropical forests. Appl. Soil Ecol., 24:17-26, 2003. 
EMPRESA BRASILEIRA DE PESQUISA AGROPECUÁRIA - EMBRAPA. Manual de métodos de análise de solo. 2.ed. Rio de Janeiro, Centro Nacional de Pesquisa de Solos, 1997. 212p.

EMPRESA BRASILEIRA DE PESQUISA AGROPECUÁRIA EMBRAPA. Centro Nacional de Pesquisa de Solos. Sistema brasileiro de classificação de solos. Rio de Janeiro, Embrapa-SPI, 2006. 306p.

GAMA-RODRIGUES, A.C. \& BARROS, N.F. Ciclagem de nutrientes em floresta natural e em plantios de eucalipto e de dandá no sudeste da Bahia, Brasil. R. Árvore, 26:193207, 2002.

GOLDEWIJK, K.K. \& RAMANKUTTY, N. Disponível em: $<$ http://www.eolss.net/outlinecomponents/Land-UseLand-Cover-Soil-Sciences.aspx>. Acesso em: 17 sbril 2012.

HÄTTENSCHWILER, S. \& JØRGENSEN, H.B. Carbon quality rather than stoichiometry controls litter decomposition in a tropical rain forest. J. Ecol., 98:754-763, 2010.

JACKSON, L.E.; BURGER, M. \& CAVAGNARO, T.R. Roots, nitrogen transformations, and ecosystem services. Ann. Rev. Plant Biol., 59:341-63, 2008.

JOERGENSEN, R.G. \& BROOKES, P.C. Ninhydrin-reactive nitrogen measurements of microbial biomass in $0.5 \mathrm{M}$ $\mathrm{K}_{2} \mathrm{SO}_{4}$ soil extracts. Soil Biol. Biochem., 22:1023-1027, 1990 .

KASCHUK, G.; ALBERTON, O. \& HUNGRIA, M. Three decades of soil microbial biomass studies in Brazilian ecosystems: Lessons learned about soil quality and indications for improving sustainability. Soil Biol. Biochem., 42:1-13, 2010.

KEENEY, D.R. \& NELSON, D.W. Nitrogen-inorganic forms. In: PAGE, A.L. \& MILLER, R.H., eds. Methods of soil analysis, chemical and microbiological properties. 2.ed. Madison, American Society of Agronomy, 1982. Part 2. p.643-698.

MENDES FILHO, P.F.; VASCONCELLOS, R.L.F.; PAULA, A.M. \& CARDOSO, E.J.B.N. Evaluating the potential of forest species under microbial management for the restoration of degraded mining areas. Water Air Soil Pollut., 208:79-89, 2010.

MONTEIRO, M.T. \& GAMA-RODRIGUES, E.F. Carbono, nitrogênio e atividade da biomassa microbiana em diferentes estruturas de serapilheira de uma floresta natural. R. Bras. Ci. Solo, 28:819-826, 2004.

MURPHY, J. \& RILEY, J.P. A modified single solution method for the determination of phosphate in natural waters. Anal. Chim. Acta., 27:31-36, 1962.

MURTY, D.; KIRSCHBAUM, M.U.F.; McMURTRIE, R.E. \& McGILVRAY, H. Does conversion of forest to agricultural land change soil carbon and nitrogen? A review of literature. Global Change Biol., 8:105-123, 2002.

NAYAK, D.R.; BABU, Y.J. \& ADHYA, T.K. Long-term application of compost influences microbial biomass and enzyme activities in a tropical Aeric Endoaquept planted to rice under flooded condition. Soil Biol. Biochem., 39:1897-1906, 2007.
NDAW, S.M.; GAMA-RODRIGUES, A.C.; GAMARODRIGUES, E.F.; SALES, K.R.N. \& ROSADO, A.S. Relationships between bacterial diversity, microbial biomass, and litter quality in soils under different plant covers in northern Rio de Janeiro State, Brazil. Can. J. Microbiol., 55:1089-1095, 2009.

NOGUEIRA, M.A.; ALBINO, U.B.; BRANDÃO-JUNIOR, O.; BRAUN, G.; CRUZ, M.F.; DIAS, B.A.; DUARTE, R.T.D.; GIOPPO, N.M.R.; MENNA, P.; ORLANDI, J.M.; RAIMAM, M.P.; RAMPAZO, L.G.L.; SANTOS, M.A.; SILVA, M.E.Z.; VIEIRA, F.P.; TOREZAN, J.M.D.; HUNGRIA, M. \& ANDRADE, G. Promising indicators for assessment of agroecosystems alteration among natural, reforested and agricultural land use in southern Brazil. Agric. Ecosyst. Environ., 115:237-247, 2006.

OLIVEIRA, J.B. Solos do Estado de São Paulo: Descrição das classes registradas no mapa pedológico. Campinas, Instituto Agronômico de Campinas, 1999. 112p. (Boletim Científico, 45)

PENGTHAMKEERATI, P.; MOTAVALLI, P.P. \& KREMER, R.J. Soil microbial activity and functional diversity changed by compaction, poultry litter and cropping in a claypan soil. Appl. Soil Ecol., 48:71-80, 2011.

PRESCOTT, C. Do rates of litter decomposition tell us anything we really need to know? For. Ecol. Manage., 220:66-74, 2005.

RAIJ, B.van; ANDRADE, J.C.; CANTARELLA, H. \& QUAGGIO, J.A. Análise química para avaliação da fertilidade de solos tropicais. Campinas, Instituto Agronômico de Campinas, 2001. 284p.

REICHERT, J.M.; REINERT, D.J. \& BRAIDA, J.A. Qualidade dos solos e sustentabilidade agrícola. Ci. Amb., 27:2948, 2003.

RIBEIRO, M.C.; METZGER, J.P.; MARTENSEN, A.C.; PONZINI, F.J. \& HIROTA, M.M. The Brazilian Atlantic Forest: How much is left, and how is the remaining forest distributed? Implications for conservation. Biol. Conserv., 142:1141-1153, 2009.

RODRIGUES, R.R.; LEITÃO-FILHO, H.F. \& CRESTANA, M.S.M. Recomposição artificial da mata ciliar ao redor da represa de abastecimento de água do município de Iracemápolis, SP. In: Plano diretor de manejo e uso da bacia hidrográfica do Ribeirão Cachoeirinha, município de Iracemápolis. 1987. p.59-91.

SANTOS, K. \& KINOSHITA, L.S. Flora arbustivo-arbórea do fragmento de floresta estacional semidecidual do Ribeirão Cachoeira, município de Campinas, SP. Acta Bot. Bras.,17:325-341, 2003.

SAS Institute. SAS/STAT: User's guide statistics. Version 9.2. Cary, 1999 .

SILVA, S.R.; SILVA, I.R.; BARROS, N.F. \& MENDONÇA, E.S. Effect of compaction on microbial activity and carbon and nitrogen transformations in two Oxisols with different mineralogy. R. Bras. Ci. Solo, 34:11411149, 2011. 
SIQUEIRA NETO, M.; PICCOLO, M.C.; VENZE FILHO, S.P.; FEIGL, B.J. \& CERRI, C.C. Mineralização e desnitrificação do nitrogênio no solo sob sistema plantio direto. Bragantia, 69:923-936, 2010.

SOUZA, L.M.; SCHLEMMER, F.; ALENCAR, P.M.; LOPES, A.A.C.; PASSOS, S.R.; XAVIER, G.R.; FERNANDES, M.F.; MENDES, I.C. \& REIS JUNIOR, F.B. Estrutura metabólica e genética de comunidades bacterianas em solo de cerrado sob diferentes manejos. Pesq. Agropec. Bras., 47:269-276, 2012
TABATABAI, M.A. \& BREMNER, J.M. Use of $p$-nitrofenol phosphate for assay of soil phosphatase activity. Soil Biol. Biochem., 1:301-307, 1969.

TER BRAAK, C.J.F. \& SMILAUER, P. Canoco-reference manual and user's guide to Canoco for windows: Software for canonical Community Ordination (Version 4.5). Ithaca, Microcomputer Power, 1998. 332p.

VANCE, E.D.; BROOKES, P.C. \& JENKINSON, D.S. An extraction method for measuring soil microbial biomassC. Soil Biol. Biochem., 19:703-707, 1987. 